\title{
To Biopsy or Not to Biopsy: Evaluation of a Large German Cohort of Patients with Abnormal Liver Tests of Unknown Etiology
}

\author{
Johannes Wilhelm Rey ${ }^{a, c}$ Antje Jahn-Eimermacher ${ }^{b}$ Veronika Doernberger ${ }^{a}$ \\ Ana Paula Barreiros ${ }^{a, d}$ Markus Krupp ${ }^{a}$ Arthur Hoffman ${ }^{a, c}$ Ralf Kiesslich ${ }^{a, c}$ \\ Martina Müller-Schilling ${ }^{d}$ Peter Robert Galle ${ }^{a} \quad$ Andreas Teufel $^{a}, d$ \\ ${ }^{a}$ First Department of Internal Medicine, and ${ }^{b}$ Institute for Medical Biostatistics, Epidemiology and Informatics, \\ University Medical Center Mainz, Mainz, 'D Department of Internal Medicine, St. Mary's Hospital Frankfurt, Frankfurt, \\ and d Department of Internal Medicine I, University Hospital Regensburg, Regensburg, Germany
}

\section{Key Words}

Liver chemistry test - Aminotransferases - Glutamate dehydrogenase - Aspartate aminotransferase $\cdot$ Ferritin . Unclear hepatopathy · Non-alcoholic fatty liver disease . Liver biopsy

\footnotetext{
Abstract

Background and Aims: Despite increasingly sensitive and accurate blood tests to detect liver disease, liver biopsy remains very useful in patients with atypical clinical features and abnormal liver tests of unknown etiology. The aim was to determine those elevated laboratory liver parameters that cause the clinician to order a biopsy, and whether laboratory tests are associated with pathological findings on histology. Methods: 504 patients with unclear hepatopathy, admitted to the outpatient clinic of a university hospital between 2007 and 2010, were analyzed with respect to laboratory results, clinical data, and the results of liver biopsies. Results: Aspartate aminotransferase (AST) and glutamate dehydrogenase (GLDH) levels above the normal range significantly increased the likelihood of recommending a liver biopsy by $81 \%$ [OR with $95 \% \mathrm{Cl} 1.81$ (1.21-2.71), $\mathrm{p}=0.004$ ] and 159\% [OR with
}

$95 \% \mathrm{Cl} 2.59$ (1.70-3.93), $\mathrm{p}<0.001]$, respectively. AST values above normal were associated with fibrosis ( 63 vs. $40 \%$ for normal AST, $p=0.010$ ). Elevated ferritin levels pointed to a higher incidence of steatosis ( $48 \mathrm{vs.} 10 \%$ for normal ferritin, $\mathrm{p}<0.001$ ) and inflammation (87 vs. $62 \%$ for normal ferritin, $p=0.004)$. Conclusions: Our results indicate that elevated AST and GLDH were associated with a greater likelihood of recommending liver biopsy. Elevated AST and ferritin levels were associated with steatosis, inflammation and fibrosis on liver biopsies. Thus, AST and ferritin may be useful non-invasive predictors of liver pathology in patients with unclear hepatopathy.

(c) 2014 S. Karger AG, Basel

\section{Introduction}

Liver enzymes and cholestasis parameters are widely used for screening and monitoring hepatobiliary disorders. Elevated liver enzymes are rather common, at least in Western countries. It has been suggested that $10-25 \%$ of German adults have increased alanine aminotransferase (ALT) levels [1]. An abnormal liver chemistry has

\section{KARGER}

E-Mail karger@karger.com www.karger.com/dig (c) 2014 S. Karger AG, Basel

0012-2823/14/0894-0310\$39.50/0
Johannes Wilhelm Rey, MD

St. Mary's Hospital Frankfurt

Richard-Wagner-Strasse 14

DE-60318 Frankfurt (Germany)

E-Mail johannes.wilhelm.rey@t-online.de 
been reported in $1-4 \%$ of asymptomatic individuals and is commonly discovered incidentally in routine laboratory testing [2]. The dilemma of testing for ALT is that elevated ALT levels have been identified in patients without liver disorders [3], but increased liver enzymes were also closely linked with liver disease and pathological changes in liver tissue.

One of the most common diagnoses in patients with abnormal ALT values is fatty liver disease [4]. A population-based survey in the United States showed abnormal ALT values in $8.9 \%$ of persons; this may be related to the greater prevalence of obesity in the last few years [5]. ALT levels were shown to correlate with the body mass index (BMI), increasing significantly over time [6]. However, the latter study contained many patients (45\%) whose elevations remained unexplained. ALT was increased in the majority of, but not all, German patients with acute and chronic liver disease [1]. It may even be of predictive value for survival. Screening for elevated liver enzyme activity in a large German cohort of construction workers demonstrated a strong relationship between elevated liver parameters, early retirement, and mortality $[7,8]$. Furthermore, elevated serum levels of aspartate aminotransferase (AST) and ALT registered in routine medical care were reported to be associated with future mortality in community residents [9].

Liver biopsy is a diagnostic gold standard, and is performed to establish a precise diagnosis in patients with long-term elevations in liver parameters. However, a liver biopsy involves the risk of bleeding, perforation, and infection [10]. Given the low prevalence of clinically significant liver disease - a mere $1 \%$ of patients - and the limited value of blood tests for distinguishing between patients with severe and those with benign liver disease, more precise prediction of the need for liver biopsy would be a significant step forward in the diagnostic algorithm of liver disease. A liver biopsy is considered mandatory to establish the diagnosis in asymptomatic patients with elevated ALT levels [11]. Nevertheless, a rational approach to liver biopsy is most urgently needed [12].

Independent of published recommendations, the decision to perform a liver biopsy is a major diagnostic step. In a prospective investigation of patients with abnormal serum aminotransferase levels, liver biopsies revealed steatosis or steatohepatitis in $84 \%$. An initial dietary treatment approach was used in these patients, resulting in considerable weight loss. It proved to be an effective treatment in many patients and obviated the need for liver biopsy [13]. In a further study comprising 36 patients with chronic elevations of serum ALT, AST or alkaline phosphatase (AP) levels, the liver biopsy changed the diagnosis in just 5 individuals, and influenced the treatment in 12 patients. The authors concluded that the risks and benefits of liver biopsy should be weighed carefully, especially when investigational therapies are not available [14]. Hay et al. [15] described 47 patients with chronic elevated aminotransferase levels, who underwent full evaluation and liver biopsies. The patients had no clinical symptoms of liver disease. Steatohepatitis was diagnosed in 10 patients while chronic hepatitis was established in 34, of whom 16 had evidence of cirrhosis on biopsy and 3 had miscellaneous diagnoses. Nonetheless, in some cases liver biopsy provides meager additional information, such as in patients with mild fibrosis [16]. It has also been mentioned that patients with elevated liver enzymes may have a normal liver histology [17].

Liver biopsy and histological assessment of the liver remains an important diagnostic tool in clinical management. The current AASLD recommendations for liver biopsy mention three major categories: (a) for diagnosis, (b) for the assessment of prognosis (disease staging), and/ or (c) to assist in making therapeutic decisions [18].

To determine suitable candidates for liver biopsy, we evaluated the impact of abnormal liver chemistry on the decision to perform liver biopsies. This was a retrospective single-center assessment of patients who presented at our outpatient hepatology department.

\section{Methods}

Patient Cohort

Patients with a medical history of unclear hepatopathy and negative tests for viral hepatitis $\mathrm{A}, \mathrm{B}$, or $\mathrm{C}$, referred by general practitioners and treated at the outpatient hepatology department of the University Medical Center of Mainz between 2007 and 2010, were analyzed retrospectively. Of 504 patients, 240 (47.6\%) were male and 264 (52.4\%) were female. Patients with known preexisting hepatic conditions such as autoimmune hepatitis, primary biliary cirrhosis, primary sclerosing cholangitis, frequent alcohol consumption, or liver cirrhosis were excluded. Patients with a positive CMV test were also excluded. Data were obtained from patient files in the SAP ${ }^{\mathrm{TM}}$ hospital information system, discharge summaries, history sheets, and ultrasound investigation. The patients' BMI, laboratory values, date of birth, and gender were registered. Pathological data concerning steatosis, fibrosis, inflammation, and cirrhosis were taken from the medical files.

\section{Data Analysis}

Microsoft Excel ${ }^{\mathrm{TM}}$ and SPSS 17 for Windows ${ }^{\mathrm{TM}}$ were used for data archiving and analysis. Patients who underwent liver biopsy directly after initial presentation or within a 6-month period when elevated liver enzymes did not improve were identified as those recommended to undergo a biopsy. All other pa- 
Table 1. Suspected diagnoses leading to referral to a university hospital outpatient clinic

\begin{tabular}{lcr}
\hline & Patients & $\%$ \\
\hline Unspecific hepatitis & 3 & 0.6 \\
Liver cirrhosis & 1 & 0.2 \\
NAFLD & 90 & 17.9 \\
Toxic hepatopathy & 11 & 2.2 \\
Unclear hepatopathy & 399 & 79.2 \\
\hline
\end{tabular}

tients were considered to have received no recommendation for a biopsy. Laboratory data were classified as normal, reduced, or increased.

\section{Statistics}

In univariate analyses we compared, for each parameter, the relative frequency of a recommendation to undergo a biopsy between patients within and out of the normal range of the parameter by performing $\chi^{2}$ tests. The same type of analysis was performed to compare relative frequencies of abnormal pathological findings between groups. For multivariate analyses we used mul-

Table 2. Summary of laboratory data

Acute-phase proteins

Antibodies
C-reactive protein, ceruloplasmin, haptoglobin, transferrin

Anti-gliadin antibodies, antimitochondrial antibodies, antimitochondrial antibodies-M2, anti-cyclic citrullinated peptide antibody (IgG), centrally accentuated antineutrophil cytoplasmic antibody, perinuclear antineutrophil cytoplasmic antibody, antinuclear antibodies, anti-double-stranded DNA antibody, liver kidney microsomal antibodies, antibody against soluble liver antigen, smooth muscle antibody, immunoglobulin A, immunoglobulin D, immunoglobulin E, immunoglobulin G, immunoglobulin $\mathrm{M}$, HIV antigen/antibody test, rheumatoid factor, nuclear deoxyribonucleic acid, myeloperoxidase antibody, parietal cell antibody, antiproteinase-3 antibody

Blood count Basophil granulocytes, polymorphonuclear leukocytes, band neutrophils, erythrocytes, red blood cell distribution width, hematocrit, hemoglobin, leukocytes, lymphocytes, thrombocytes, mean platelet volume, mean corpuscular hemoglobin, mean corpuscular volume, monocytes, neutrophilic leukocytes

\begin{tabular}{l} 
Cholestasis parameters \\
\hline Coagulation \\
\hline Complement system \\
\hline Copper metabolism \\
\hline Electrolytes \\
\hline Electrophoresis \\
Enzymes
\end{tabular}
$\gamma$-Glutamyl transferase, alkaline phosphatase Fibrinogen, prothrombin time, partial thromboplastin time, D-dimer C4 Copper, ceruloplasmin Calcium, chloride, potassium, magnesium, sodium $\alpha$-Globulins, $\alpha_{2}$-globulins, $\alpha_{2}$-macroglobulin, $\beta$-globulin, $\gamma$-globulin Muscle-brain type creatinine kinase, creatinine kinase, glutamate dehydrogenase, lactate dehydrogenase

\begin{tabular}{ll}
\hline Excretory activity & Bilirubin \\
\hline Glycoproteins & $\alpha_{1}$-Proteinase inhibitor \\
\hline
\end{tabular}

Hemochromatosis parameters $\quad$ Ferritin, iron, transferrin

Hepatitis serology

Antihepatitis A IgG and IgM antibodies, surface antigen of the hepatitis B virus, antibody to the hepatitis B surface antigen, antibody against hepatitis C virus, antibody to hepatitis B core antigen

Infectiology Anticytomegalovirus antibodies, IgG and IgM

Liver function parameters

Metabolism of lipids

Other Albumin, cholinesterase, prothrombin time

Apolipoprotein A1, apolipoprotein B, cholesterol, high-density lipoprotein cholesterol, low-density lipoprotein cholesterol, HDL/LDL quotient, triglycerides Glucose, phosphate

Pancreatic function parameters $\quad \alpha$-Amylase, lipase

Proteins, metabolites Total protein, uric acid, urea

Renal function parameters Creatinine

Thyroid parameters $\quad$ Free thyroxine, thyroid-stimulating hormone, triiodothyronine, antithyroid peroxidase antibodies, antithyroglobulin antibodies

Transaminases

Aspartate aminotransferase, alanine aminotransferase

Tumor markers 
tiple logistic regressions to identify those variables that made the most important contribution to the recommendation for a liver biopsy. Hosmer-Lemeshow test statistics and the area under the receiver operating curve were used to determine the quality of model fitting and discrimination, respectively. As this was an exploratory study, all analyses were considered exploratory; $\mathrm{p}$ values were only given for descriptive reasons.

\section{Results}

Laboratory Data in a Large Cohort of Hepatitis A-, B-, or C-Negative Patients with Elevated 'Liver Enzymes'

We analyzed, in a retrospective single-center study, 504 patients who attended our hepatology outpatient center; 240 patients (47.6\%) were male and 264 (52.4\%) were female. Unclear hepatopathy was suspected on clinical investigation in 399 patients (79.2\%) prior to their admission to the hospital. Non-alcoholic fatty liver disease (NAFLD) was suspected in 90 patients (17.9\%) (table 1). The patients' medical records revealed 149 registered laboratory parameters (table 2). Excluding unavailable patient records, laboratory values were evaluated for 473 patients. In addition to BMI and age, nine liver laboratory parameters known to be indicators of liver function were selected (table 3a). Median values of AP, bilirubin and ferritin were in the normal range. In contrast, glutamate dehydrogenase(GLDH), AST, ALT, $\gamma$-glutamyl transferase $(\gamma-G T)$, prothrombin time and platelet agents were above the upper limit of normal. The patients' median BMI was 27 (min. 18, max. 44) and their median age 48 years (min. 15 years, max. 87 years). Abnormal metabolic values were seen in $24.5-32.3 \%$ of patients (table 3b).

\section{Ultrasound of the Liver}

$421(83.5 \%)$ patients underwent ultrasound investigation of the liver. Hepatic steatosis was suspected in 262 $(62.3 \%)$ and cirrhosis in 10 patients (2.4\%); 78 patients (18.5\%) had no pathological findings on ultrasound. Doppler ultrasound findings were not evaluated.

\section{Single Liver Enzymes and the Indication for Liver Biopsy}

Among the selected blood parameters, median values of ALT, AST, $\gamma$-GT, GLDH, prothrombin time, and platelet agents were above normal (table 3a). These and three additional variables were analyzed with regard to their role in the decision to perform a liver biopsy. Table 4 summarizes univariate analyses of the association among these variables and the recommendation for bi-
Table 3. Descriptive values of laboratory tests, age and BMI, selected for analysis, (a) and metabolic values (b)

a

\begin{tabular}{lllll}
\hline & $\begin{array}{l}\text { Values, } \\
\mathrm{n}\end{array}$ & $\begin{array}{l}\text { Mini- } \\
\text { mum }\end{array}$ & Median & $\begin{array}{l}\text { Maxi- } \\
\text { mum }\end{array}$ \\
\hline BMI & 346 & 18 & 27 & 44 \\
\hline Age, years & 504 & 15 & 48 & 87 \\
\hline AP, U/l & 493 & 30 & 84 & 701 \\
\hline GLDH, U/l & 473 & 1.4 & 9.65 & 314.9 \\
\hline AST, U/l & 500 & 17 & 39 & 1,290 \\
\hline ALT, U/l & 499 & 13 & 68 & 1,283 \\
\hline Bilirubin, mg/dl & 491 & 0.17 & 0.6 & 13.59 \\
\hline -GT, U/l & 494 & 9 & 95 & 1,631 \\
\hline Ferritin, ng/ml & 440 & 4 & 116 & 4,503 \\
\hline Prothrombin time, /s & 490 & 16 & 104 & 127 \\
\hline Thrombocytes, /nl & 498 & 54.00 & 285 & 631.00 \\
\hline
\end{tabular}

b

\begin{tabular}{lll}
\hline Variable & Normal range & $\mathrm{n}(\%)$ \\
\hline HDL & $>40$ & $327(73.2)$ \\
& $\leq 40$ & $120(26.8)$ \\
LDL & $<160$ & $320(75.5)$ \\
& $\geq 160$ & $104(24.5)$ \\
Cholesterol & $<200$ & $306(67.7)$ \\
Triglycerides & $\geq 200$ & $146(32.3)$ \\
& $<200$ & $327(72.3)$ \\
& $\geq 200$ & $125(27.7)$ \\
\hline
\end{tabular}

opsy. Transaminases, GLDH and ferritin differed significantly in their contribution to the recommendation to perform a liver biopsy when the respective values were above the normal range. Specifically, above-normal GLDH levels influenced the recommendation to undergo a liver biopsy in $61 \%$ of cases, compared to $33 \%$ in patients with normal GLDH levels. For multivariate analysis, thrombocytes, AP, GLDH, AST, ALT, $\gamma$-GT, bilirubin, prothrombin time, ferritin and gender were analyzed with respect to their impact on performing a biopsy. All other parameters [BMI, ultrasound, cholesterol, albumin, cholinesterases, lactodehydrogenase (LDH)] were excluded because of the large number of missing values and because univariate analyses indicated their minimal impact on the decision to perform a biopsy. Forward and backward stepwise logistic regression using a likelihood ratio $\mathrm{p}$ value of $\leq 5 \%$ and $>10 \%$ as variable inclusion and exclusion criterion, respectively, both identified an AST value above the nor- 
Table 4. Fifteen laboratory and clinical parameters and their influence on the decision to perform a liver biopsy

\begin{tabular}{|c|c|c|c|c|c|}
\hline Variable & Values, $\mathrm{n}$ & $\begin{array}{l}\text { Normal } \\
\text { range }\end{array}$ & $\begin{array}{l}\text { All patients, } \\
\mathrm{n}\end{array}$ & $\begin{array}{l}\text { Number }(\%) \text { of patients } \\
\text { with recommendation } \\
\text { for a biopsy }\end{array}$ & $\begin{array}{l}\mathrm{p} \text { value } \\
\left(\chi^{2} \text { test }\right)\end{array}$ \\
\hline $\mathrm{AP}, \mathrm{U} / \mathrm{l}$ & 493 & $\begin{array}{l}\leq 130 \\
>130\end{array}$ & $\begin{array}{r}413 \\
80\end{array}$ & $\begin{array}{r}200(48) \\
48(60)\end{array}$ & 0.076 \\
\hline$\overline{\mathrm{GLDH}}, \mathrm{U} / \mathrm{l}$ & 473 & $\begin{array}{l}\leq 7 \\
>7\end{array}$ & $\begin{array}{l}169 \\
304\end{array}$ & $\begin{array}{r}55(33) \\
184(61)\end{array}$ & $<0.001$ \\
\hline$\overline{\mathrm{AST}}, \mathrm{U} / \mathrm{l}$ & 500 & $\begin{array}{l}\leq 35 \\
>35\end{array}$ & $\begin{array}{l}208 \\
292\end{array}$ & $\begin{array}{r}79(38) \\
171(59)\end{array}$ & $<0.001$ \\
\hline$\overline{\mathrm{ALT}}, \mathrm{U} / \mathrm{l}$ & 499 & $\begin{array}{l}\leq 50 \\
>50\end{array}$ & $\begin{array}{l}146 \\
353\end{array}$ & $\begin{array}{r}51(35) \\
199(56)\end{array}$ & $<0.001$ \\
\hline$\gamma$-GT, U/l & 494 & $\begin{array}{l}\leq 60 \\
>60\end{array}$ & $\begin{array}{l}138 \\
356\end{array}$ & $\begin{array}{r}52(38) \\
198(56)\end{array}$ & $<0.001$ \\
\hline Ferritin, ng/ml & 440 & $\begin{array}{l}\leq 200 \\
>200\end{array}$ & $\begin{array}{l}289 \\
151\end{array}$ & $\begin{array}{r}131(45) \\
88(58) \\
\end{array}$ & 0.013 \\
\hline Prothrombin time, $\%$ & 490 & $\begin{array}{l}\geq 70 \\
<70\end{array}$ & $\begin{array}{r}470 \\
20\end{array}$ & $\begin{array}{r}239(51) \\
9(45)\end{array}$ & 0.776 \\
\hline Bilirubin, mg/dl & 491 & $\begin{array}{l}\leq 1.2 \\
>1.2\end{array}$ & $\begin{array}{r}437 \\
54\end{array}$ & $\begin{array}{r}219(50) \\
30(56) \\
\end{array}$ & 0.542 \\
\hline Thrombocytes, /nl & 498 & $\begin{array}{l}\geq 150 \\
<150\end{array}$ & $\begin{array}{r}480 \\
18\end{array}$ & $\begin{array}{r}240(50) \\
11(61)\end{array}$ & 0.493 \\
\hline Gender & 504 & $\begin{array}{l}\text { male: } \\
\text { female: }\end{array}$ & $\begin{array}{l}240 \\
264\end{array}$ & $\begin{array}{l}124(52) \\
128(49)\end{array}$ & 0.532 \\
\hline Albumin, $\mathrm{g} / \mathrm{l}$ & 450 & $\begin{array}{l}\geq 35 \\
<35\end{array}$ & $\begin{array}{r}434 \\
16\end{array}$ & $\begin{array}{r}223(51) \\
7(44)\end{array}$ & 0.73 \\
\hline Cholinesterases, kU/l & 449 & $\begin{array}{l}\geq 5 \\
<5\end{array}$ & $\begin{array}{r}443 \\
6\end{array}$ & $\begin{array}{r}223(50) \\
4(67)\end{array}$ & - \\
\hline$\overline{\mathrm{LDH}}, \mathrm{U} / \mathrm{l}$ & 456 & $\begin{array}{l}\leq 250 \\
>250\end{array}$ & $\begin{array}{r}362 \\
94\end{array}$ & $\begin{array}{r}178(49) \\
52(55) \\
\end{array}$ & 0.344 \\
\hline Cholesterol, mg/dl & 452 & $\begin{array}{l}\leq 200 \\
>200\end{array}$ & $\begin{array}{l}148 \\
304\end{array}$ & $\begin{array}{r}75(51) \\
153(50)\end{array}$ & 0.975 \\
\hline Ultrasound & 421 & $\begin{array}{l}\text { no } \\
\text { yes }\end{array}$ & $\begin{array}{r}78 \\
343\end{array}$ & $\begin{array}{r}39(50) \\
175(51)\end{array}$ & 0.97 \\
\hline
\end{tabular}

mal range ( $>35 \mathrm{U} / \mathrm{l})$ and a GLDH value above the normal range $(>7 \mathrm{U} / \mathrm{l})$ as those variables that contributed markedly to the recommendation to perform a liver biopsy. A final model including only these two factors as independent variables was fitted to account for missing values in non-selected variables. The final model, based on the data of 473 patients, indicated that AST levels above the normal range increased the risk by $81 \%$ [OR with 95\% CI $1.81(1.21-2.71), \mathrm{p}=0.004]$ and a GLDH above the normal range increased the risk of recommending a liver biopsy by $159 \%$ [OR with $95 \%$ CI 2.59 $(1.70-3.93), \mathrm{p}<0.001]$. Model fit was rated well according to a Hosmer-Lemeshow test statistic of $\chi^{2}=0.01$ $(\mathrm{p}=0.995)$, whereas discrimination was only moderate, with an area under the receiver operating curve of 0.661 (table 5).
Table 5. Logistic regression model with GLDH and AST as the independent variables associated with the recommendation to undergo a biopsy (dependent variable) $(n=473)$

\begin{tabular}{llc}
\hline Variable & OR $(95 \% \mathrm{CI})$ & $\mathrm{p}$ (Wald test) \\
\hline GLDH $(>7$ vs. $\leq 7)$ & $2.59(1.70-3.93)$ & $<0.001$ \\
AST $(>35$ vs. $\leq 35)$ & $1.81(1.21-2.71)$ & 0.004 \\
\hline
\end{tabular}

\section{Liver Biopsy}

In 201 patients (39.9\%), liver biopsy was recommended immediately after the clinical consultation of a hepatologist at our outpatient center. 162 patients (32.1\%) underwent a liver biopsy after their first consultation. These patients had various stages of steatosis, inflammation, or 
Table 6. Comparison of the results of liver biopsy between patients with and without normal values for GLDH, AST, ALT, $\gamma$-GT and ferritin

\begin{tabular}{|c|c|c|c|c|c|c|c|}
\hline Variable & $\begin{array}{l}\text { Normal } \\
\text { range }\end{array}$ & $\begin{array}{l}\text { All patients, } \\
\mathrm{n}\end{array}$ & $\begin{array}{l}\text { Steatosis, } \\
\mathrm{n}(\%)\end{array}$ & $\begin{array}{l}\text { Foci, } \\
\text { n (\%) }\end{array}$ & $\begin{array}{l}\text { Fibrosis, } \\
\mathrm{n}(\%)\end{array}$ & $\begin{array}{l}\text { Cirrhosis, } \\
\mathrm{n}(\%)\end{array}$ & $\begin{array}{l}\text { Any result, } \\
\mathrm{n}(\%)\end{array}$ \\
\hline \multirow[t]{3}{*}{ GLDH } & $\leq 7$ & 40 & $8(20)$ & $30(75)$ & $24(60)$ & $6(15)$ & $36(90)$ \\
\hline & $>7$ & 113 & $25(22)$ & 77 (68) & $60(53)$ & $12(11)$ & $97(86)$ \\
\hline & & & $\mathrm{p}=0.955$ & $\mathrm{p}=0.540$ & $\mathrm{p}=0.569$ & $\mathrm{p}=0.650$ & $\mathrm{p}=0.691$ \\
\hline \multirow[t]{3}{*}{ AST } & $\leq 35$ & 53 & $9(17)$ & 31 (59) & $21(40)$ & $4(8)$ & $42(79)$ \\
\hline & $>35$ & 107 & $26(24)$ & $80(75)$ & $67(63)$ & $14(13)$ & $97(91)$ \\
\hline & & & $\mathrm{p}=0.395$ & $\mathrm{p}=0.055$ & $\mathrm{p}=0.010$ & $\mathrm{p}=0.437$ & $\mathrm{p}=0.078$ \\
\hline \multirow[t]{3}{*}{ ALT } & $\leq 50$ & 37 & $6(16)$ & $22(69)$ & $18(49)$ & $5(14)$ & $30(81)$ \\
\hline & $>50$ & 123 & $29(24)$ & $89(72)$ & $70(57)$ & $13(11)$ & 109 (89) \\
\hline & & & $\mathrm{p}=0.470$ & $\mathrm{p}=0.197$ & $\mathrm{p}=0.486$ & $\mathrm{p}=0.841$ & $\mathrm{p}=0.361$ \\
\hline \multirow[t]{3}{*}{$\gamma$-GT } & $\leq 60$ & 32 & $10(31)$ & $25(78)$ & $17(53)$ & $4(13)$ & $29(91)$ \\
\hline & $>60$ & 128 & $25(20)$ & $86(67)$ & $71(56)$ & $14(11)$ & $110(86)$ \\
\hline & & & $\mathrm{p}=0.232$ & $\mathrm{p}=0.324$ & $\mathrm{p}=0.968$ & $\mathrm{p}=0.950$ & $\mathrm{p}=0.682$ \\
\hline \multirow[t]{3}{*}{ Ferritin } & $\leq 200$ & 89 & $9(10)$ & $55(62)$ & $50(56)$ & $11(12)$ & $74(83)$ \\
\hline & $>200$ & 47 & $21(48)$ & $41(87)$ & $29(62)$ & $5(11)$ & 45 (96) \\
\hline & & & $\mathrm{p}<0.001$ & $\mathrm{p}=0.004$ & $\mathrm{p}=0.661$ & $\mathrm{p}=0.987$ & $\mathrm{p}=0.066$ \\
\hline
\end{tabular}

$p$ values were calculated using a $\chi^{2}$ test.

fibrosis in $37.7,68.5$ and $54.3 \%$, respectively. Cirrhosis was found in $11 \%$ of cases. Besides, 51 patients (10.1\%) were advised to undergo a liver biopsy because their clinical and laboratory values did not improve; 303 patients did not undergo a liver biopsy (60.1\%).

\section{Laboratory Results and Pathological Findings on Liver Histology}

For any histology result (steatosis, inflammation, fibrosis, cirrhosis) compared with one of five laboratory values (GLDH, AST, ALT, $\gamma$-GT and ferritin) that had a significant influence for a recommendation for liver biopsy, no differences could be detected in the pathology result, neither in normal nor in values above the normal range (table 6).

Detailed histological results were compared to those parameters that contributed significantly to the recommendation to undergo a biopsy. AST levels above the normal range ( $>35 \mathrm{U} / \mathrm{l})$ were related to fibrosis on liver biopsy (63 vs. $40 \%, \mathrm{p}=0.010)$. Ferritin values above normal were strongly associated with pathological results for steatosis ( 48 vs. $10 \%, \mathrm{p}<0.001$ ) and inflammation ( 87 vs. $62 \%, \mathrm{p}=$ 0.004 ). Pathological data were found in $96 \%$ of patients whose ferritin was above normal, but only in $83 \%$ whose ferritin levels were normal $(\mathrm{p}=0.066)$. The most common pathological findings in parameters that contributed significantly to the recommendation to undergo liver biopsy were inflammation and fibrosis. Inflammation was detected in $67 \%$ of patients with elevated $\gamma$-GT and in $87 \%$ with elevated ferritin levels. Fibrosis was seen in $63 \%$ of patients with AST levels above normal and in 53\% of patients with elevated GLDH. When $\gamma$-GT and GLDH were elevated, pathological data of any type were noted in $86 \%$ of patients.

\section{Discussion}

Diagnostic evaluation of patients with unexplained liver pathologies still is a challenge for the gastroenterologist. The specificity of parameters used to determine liver disease is low. In clinical routine, patients with (marginally) elevated liver enzymes frequently reveal no serious liver pathologies [13]. In a recent study, NAFLD was reported to be the most common diagnosis in patients with elevated liver enzymes [19]. ALT was reported to correlate with BMI [20]. Elevated liver enzymes were shown to be associated with higher mortality. Thus, patients with a serious liver condition must be identified promptly. About one fifth of our patients had abnormal metabolic values (table $3 \mathrm{~b}$ ), although the median BMI of all patients was 27. However, our data provide no confirmation of the thesis that obesity and elevated cholesterol levels influenced the decision to perform a liver biopsy, although these parameters are hallmarks of NAFLD or NASH. 
An ultrasound investigation was performed in $83.5 \%$ of patients. Hepatic steatosis was suspected in $62.3 \%$ and liver cirrhosis in a mere $2.4 \%$. Of 162 patients who underwent liver biopsy directly after the initial consultation, $37.7 \%$ had hepatic steatosis on histopathological investigation. This amounted to a lower prevalence of pathological findings than reported previously [21]. These differences may be explained by the fact that liver biopsies are liberally recommended at our outpatient center. However, our results indicate that a substantial number of patients with unclear hepatopathy had steatosis in their liver biopsy specimens. Despite contrary reports, the most common histological findings in our study were inflammation and fibrosis [21]. Thus, some patients with unclear hepatopathy appear to have been in advanced stages of liver damage at the time of biopsy. This highlights the importance of performing liver biopsy on a timely basis, especially with respect to its therapeutic consequences [18]. In our data, the most common pathological findings on liver chemistry were those of ALT, AST, $\gamma$-GT and GLDH. Bilirubin levels were normal.

ALT is an unreliable parameter because it varies in relation to gender, age, and other factors. It is also unreliable because of various reference standards used in laboratories. Therefore, comparing values across laboratories may not be helpful [22]. In our analysis, an increase in ALT did not affect the decision to perform liver biopsy alone. It has been suggested that ALT may be a better indicator of liver disease because of its limited tissue distribution. Mild disorders of liver homeostasis are associated with the release of cytoplasmic enzymes, whereas severe injury results in greater release of cytoplasmic and mitochondrial AST. Despite these considerations, our data suggest that a rise in AST and GLDH rather than ALT or $\gamma$-GT is crucial for the decision to perform a liver biopsy. However, GLDH has been rarely investigated as a marker in unclear hepatopathy. Some recently published data provided evidence of GLDH as a biomarker in the assessment of patients with acetaminophen-induced liver injury [23].

Our results indicated that most patients who underwent liver biopsy had at least one pathological value, including those with no changes in AST, GLDH, or ferritin. It may be concluded that, notwithstanding the results of laboratory tests, liver biopsies should be performed liberally. Based on our own liberal approach, we identified pathological findings in as many as $92 \%$ of patients. Normal transaminases were no valuable criterion to exclude patients from liver biopsy [24]. In addition to laboratory data, the patient's clinical symptoms, drug history and medical history should be given priority when deciding to perform a liver biopsy [25-33].

We lack sufficient data to justify the use of non-invasive diagnostic procedures alone in patients with ambiguous liver disease. However, although it is common practice to rely on ALT and GLDH (because these parameters have been significantly linked with liver biopsy), we showed that above-normal AST and ferritin levels may be of even greater predictive value in regard of the histopathological result. In our patients, elevated ferritin levels were significantly associated with steatosis and inflammation on histopathology than normal levels of ferritin. Patients with elevated AST values had fibrosis significantly more often compared to patients with normal AST levels. It has been reported that above-normal ferritin values may be a predictor of advanced hepatic fibrosis in patients with NAFLD [34]. Although histological evaluation of the liver has become important in assessing prognosis and tailoring treatment, non-invasive techniques (such as imaging investigations or blood tests) may replace the use of liver histology in this setting, particularly for the assessment of the severity of liver fibrosis [18].

Despite these findings, our data suggest that elevated ferritin values are predictive of inflammation and hepatic steatosis in liver-biopsied patients with unclear hepatopathy. However, other authors have reported no significant difference in these parameters [35]. This may be partly due to the different sizes of patient cohorts. Ours contained more than 500 patients and was larger than the majority of sample sizes investigated so far. Thus, ferritin might be of greater importance in decision-making for liver biopsy in patients with unclear hepatopathy.

Multivariate analysis in our study showed that AST levels influenced the decision to perform a liver biopsy. AST levels above normal were predictive of fibrosis. A correlation between AST and liver fibrosis was previously studied as part of the AST-to-platelet ratio test (APRI). These data suggested the predictive value of liver fibrosis when the APRI test result rose to above 0.7. However, APRI was of limited use in the diagnosis of fibrosis in many patients [36].

The American Gastroenterology Association (AGA) recommends liver biopsy as a useful prognostic and diagnostic test in patients with elevated serum liver chemistry for longer than 6 months. However, even with a high rate of patients undergoing immediate liver biopsy on the recommendation of an experienced hepatologist, we detected a high rate of pathological findings. Thus, the decision to perform a biopsy must be adjusted to the patient's 
symptoms, liver chemistry abnormalities, age, lifestyle, the desire for prognostic information, and associated comorbid conditions [37]. According to previous reports, the principal value of biopsy tissue is to identify a pattern of injury from which diagnostic options may be considered, assessed, validated, or discarded [38]. In contrast, the AASLD recommends a liver biopsy in patients with questionable diagnoses, and when knowledge of a specific diagnosis is likely to alter the management plan. Furthermore, it has been suggested that liver histology is an important adjunct in the management of patients with known liver disease [18].

Overall, our data clearly suggest the necessity and value of routine testing of liver enzymes, as well as emphasize the need for further evaluation and a better understanding of these tests for clinical decision-making, especially with respect to liver biopsy. In the majority of cases, a change in lifestyle may be the appropriate recommendation to improve liver enzymes. However, the diagnosis of liver inflammation or liver fibrosis may highlight the urgency to determine the underlying cause of a change in liver homeostasis and closer monitoring of liver disease to prevent life-limiting conditions.
The limitations of the present study are worthy of mention. First, not all virological parameters were available in order to exclude the patients from the study. Second, liver histology was performed percutaneously and by mini-laparoscopy in the endoscopic unit. Sampling errors may have occurred in the procedures. Third, ultrasound findings are of limited value because they were evaluated retrospectively and may have been influenced by the examiner. Finally, as the patients' medical histories were not available, the influence of liver pathologies cannot be ruled out.

In conclusion, this retrospective single-center study indicated that AST and GLDH values above the normal range had the greatest influence on the attending hepatologist's decision to perform a liver biopsy. However, elevated AST and ferritin levels varied markedly in terms of the severity of steatosis, inflammation, and fibrosis in liver biopsies of patients with abnormal liver tests of unknown etiology.

\section{Disclosure Statement}

The authors have no conflicts of interest to disclose.

\section{References}

$\checkmark 1$ Wedemeyer H, Hofmann WP, Lueth S, Malinski P, Thimme R, Tacke F, Wiegand J: ALT screening for chronic liver diseases: scrutinizing the evidence (in German). Z Gastroenterol 2010;48:46-55.

2 Kundrotas LW, Clement DJ: Serum alanine aminotransferase (ALT) elevation in asymptomatic US Air Force basic trainee blood donors. Dig Dis Sci 1993;38:2145-2150.

- 3 Scola RH, Werneck LC, Prevedello DM, Toderke EL, Iwamoto FM: Diagnosis of dermatomyositis and polymyositis: a study of 102 cases. Arq Neuropsiquiatr 2000;58:789799.

4 Armstrong MJ, Houlihan DD, Bentham L, Shaw JC, Cramb R, Olliff S, Gill PS, Neuberger JM, Lilford RJ, Newsome PN: Presence and severity of non-alcoholic fatty liver disease in a large prospective primary care cohort. J Hepatol 2012;56:234-240.

5 Ioannou GN, Boyko EJ, Lee SP: The prevalence and predictors of elevated serum aminotransferase activity in the United States in 19992002. Am J Gastroenterol 2006;101:76-82.

-6 Fraser A, Longnecker MP, Lawlor DA: Prevalence of elevated alanine aminotransferase among US adolescents and associated factors: NHANES 1999-2004. Gastroenterology 2007;133:1814-1820.
-7 Arndt V, Brenner H, Rothenbacher D, Zschenderlein B, Fraisse E, Fliedner TM: Elevated liver enzyme activity in construction workers: prevalence and impact on early retirement and all-cause mortality. Int Arch Occup Environ Health 1998;71:405-412.

-8 Ioannou GN, Weiss NS, Boyko EJ, Mozaffarian D, Lee SP: Elevated serum alanine aminotransferase activity and calculated risk of coronary heart disease in the United States. Hepatology 2006;43:1145-1151.

-9 Lee TH, Kim WR, Benson JT, Therneau TM, Melton LJ 3rd: Serum aminotransferase activity and mortality risk in a United States community. Hepatology 2008;47:880-887.

10 Tannapfel A, Dienes HP, Lohse AW: The indications for liver biopsy. Dtsch Arztebl Int 2012;109:477-483.

11 Hultcrantz R, Glaumann H, Lindberg G, Nilsson LH: Liver investigation in 149 asymptomatic patients with moderately elevated activities of serum aminotransferases. Scand J Gastroenterol 1986;21:109-113.

12 Kamath PS: Clinical approach to the patient with abnormal liver test results. Mayo Clin Proc 1996;71:1089-1094; quiz 1094-1085.
13 Daniel S, Ben-Menachem T, Vasudevan G, Ma CK, Blumenkehl M: Prospective evaluation of unexplained chronic liver transaminase abnormalities in asymptomatic and symptomatic patients. Am J Gastroenterol 1999;94:3010-3014.

14 Sorbi D, McGill DB, Thistle JL, Therneau TM, Henry J, Lindor KD: An assessment of the role of liver biopsies in asymptomatic patients with chronic liver test abnormalities. Am J Gastroenterol 2000;95:3206-3210.

15 Hay JE, Czaja AJ, Rakela J, Ludwig J: The nature of unexplained chronic aminotransferase elevations of a mild to moderate degree in asymptomatic patients. Hepatology 1989;9: 193-197.

16 Poynard T, Lenaour G, Vaillant JC, Capron F, Munteanu M, Eyraud D, Ngo Y, M'Kada H, Ratziu V, Hannoun L, Charlotte F: Liver biopsy analysis has a low level of performance for diagnosis of intermediate stages of fibrosis. Clin Gastroenterol Hepatol 2012;10:657663 e657.

17 Fischer R, Rambach W: increased $\gamma$-GT, minimal changes in liver histology, abdominal complaints - a functional liver disease (in German). Leber Magen Darm 1995;25:86:8992. 
18 Rockey DC, Caldwell SH, Goodman ZD, Nelson RC, Smith AD; American Association for the Study of Liver Diseases: Liver biopsy. Hepatology 2009;49:1017-1044.

$\checkmark 19$ Bendezu Garcia RA, Casado Martin M, Lazaro Saez M, Patron Roman GO, Galvez Miras A, Rodriguez Laiz GP, Gonzalez Sanchez M, Vega Saenz JL: Liver enzymes elevation: etiologic study and efficiency of a single-act office visit (in Spanish). Gastroenterol Hepatol 2013;36:450-456.

20 Piton A, Poynard T, Imbert-Bismut F, Khalil L, Delattre J, Pelissier E, Sansonetti N, Opolon P: Factors associated with serum alanine transaminase activity in healthy subjects: consequences for the definition of normal values, for selection of blood donors, and for patients with chronic hepatitis C. MULTIVIRC group. Hepatology 1998;27:1213-1219.

21 Skelly MM, James PD, Ryder SD: Findings on liver biopsy to investigate abnormal liver function tests in the absence of diagnostic serology. J Hepatol 2001;35:195-199.

-22 Dutta A, Saha C, Johnson CS, Chalasani N: Variability in the upper limit of normal for serum alanine aminotransferase levels: a statewide study. Hepatology 2009;50:19571962.

23 Schomaker S, Warner R, Bock J, Johnson K, Potter D, Van Winkle J, Aubrecht J: Assessment of emerging biomarkers of liver injury in human subjects. Toxicol Sci 2013;132:276283.
24 Fracanzani AL, Valenti L, Bugianesi E, Andreoletti M, Colli A, Vanni E, Bertelli C, Fatta E, Bignamini D, Marchesini G, Fargion S: Risk of severe liver disease in non-alcoholic fatty liver disease with normal aminotransferase levels: a role for insulin resistance and diabetes. Hepatology 2008;48:792-798.

25 Aitken MM, Hall E, Scott L, Davot JL, Allen WM: Liver-related biochemical changes in the serum of dogs being treated with phenobarbitone. Vet Rec 2003;153:13-16.

26 Dodurka T, Kraft W: Alanine aminotransferase, aspartate aminotransferase, glutamate dehydrogenase, alkaline phosphatase and $\gamma$-glutamyltransferase in intestinal diseases of dogs (in German). Berl Munch Tierärztl Wochenschr 1995; 108:244-248.

27 Watkins PB, Kaplowitz N, Slattery JT, Colonese CR, Colucci SV, Stewart PW, Harris SC: Aminotransferase elevations in healthy adults receiving 4 grams of acetaminophen daily: a randomized controlled trial. JAMA 2006;296: 87-93.

28 Cohen JA, Kaplan MM: The SGOT/SGPT ratio - an indicator of alcoholic liver disease. Dig Dis Sci 1979;24:835-838.

29 Moussavian SN, Becker RC, Piepmeyer JL, Mezey E, Bozian RC: Serum $\gamma$-glutamyl transpeptidase and chronic alcoholism. Influence of alcohol ingestion and liver disease. Dig Dis Sci 1985;30:211-214.

30 Saha B, Maity C: Alteration of serum enzymes in primary hypothyroidism. Clin Chem Lab Med 2002;40:609-611.
31 Huang MJ, Liaw YF: Clinical associations between thyroid and liver diseases. J Gastroenterol Hepatol 1995;10:344-350.

32 Miller KK, Grinspoon SK, Ciampa J, Hier J, Herzog D, Klibanski A: Medical findings in outpatients with anorexia nervosa. Arch Intern Med 2005; 165:561-566.

33 Ozawa Y, Shimizu T, Shishiba Y: Elevation of serum aminotransferase as a sign of multiorgan disorders in severely emaciated anorexia nervosa. Intern Med 1998;37:32-39.

34 Kowdley KV, Belt P, Wilson LA, Yeh MM, Neuschwander-Tetri BA, Chalasani N, Sanyal AJ, Nelson JE; NASH Clinical Research Network: Serum ferritin is an independent predictor of histologic severity and advanced fibrosis in patients with non-alcoholic fatty liver disease. Hepatology 2012;55:77-85.

35 Uslusoy HS, Nak SG, Gulten M: Noninvasive predictors for liver fibrosis in patients with nonalcoholic steatohepatitis. World J Hepatol 2011;3:219-227.

36 Lieber CS, Weiss DG, Morgan TR, Paronetto F: Aspartate aminotransferase to platelet ratio index in patients with alcoholic liver fibrosis. Am J Gastroenterol 2006;101:1500-1508.

37 Green RM, Flamm S: AGA technical review on the evaluation of liver chemistry tests. Gastroenterology 2002;123:1367-1384.

38 Czaja AJ, Carpenter HA: Optimizing diagnosis from the medical liver biopsy. Clin Gastroenterol Hepatol 2007;5:898-907. 